\title{
Development of an innovative drug information evidence-based medicine advanced pharmacy practice experience
}

\author{
Jessica Starr, Dana Carroll (D), Kristi Kelley, Nathan Pinner (D), Lynn Stevenson (iD, Katelin Lisenby (D), Taylor Steuber \\ Auburn University Harrison School of Pharmacy, Birmingham, Alabama, United States
}

\author{
Keywords \\ Active learning \\ Distance learning \\ Experiential education \\ Evidence-based medicine \\ Correspondence \\ Jessica Starr \\ Pharmacy Practice \\ Auburn University Harrison \\ School of Pharmacy \\ 2151 Highland Avenue South \\ Suite 230, Birmingham \\ Alabama 35205 \\ United States \\ jas0003@auburn.edu
}

\begin{abstract}
Aim: To describe the development, implementation, and structure of an innovative evidencebased medicine (EBM) advanced pharmacy practice experience (APPE) rotation and evaluate student pharmacists' perceptions of the course. Methods: A five-week, EBM APPE rotation was designed by seven faculty. Students worked remotely in teams and individually to complete preand post-assessments, journal clubs, journal scans, drug information questions, and clinical debates, as well as self- and peer-assessments. Students were asked to rate their perceptions of the course on a 5-point Likert scale. Results: A total of eighteen students, precepted by seven faculty members, completed the rotation. Students completed three group journal clubs, three individual journal scans, one individual journal club, one drug information question, and one clinical debate. Students survey data indicated that confidence in EBM skills was high following the rotation. Conclusion: This EBM APPE rotation was successful. The structure of this rotation may be transferable to a variety of settings.
\end{abstract}

\section{Introduction}

As described in the Centre for the Advancement of Pharmacy Education (CAPE) educational outcomes 2013, students should be able to "critically analyse scientific literature related to drugs and disease to enhance clinical decision making" (Medina et al., 2013). These principles of evidence-based medicine (EBM), including the critical analysis of scientific literature, is integrated throughout the Doctor of Pharmacy (Pharm.D.) curriculum at the School of Pharmacy starting in the first term. Specifically, this core area of EBM is progressive, with an active learning approach utilised throughout all the first three years of the Pharm.D. curriculum. The goal is to prepare students to evaluate scientific literature to develop evidence-based care plans that are patient- or population-specific. With this in mind, a group of seven faculty preceptors developed an innovative advanced pharmacy practice experience (APPE) in EBM. The aim was to create an alternative APPE experience that not only met the CAPE educational outcomes 2013 (Medina et al., 2013) and American Council for Pharmacy Education (ACPE) Standards 2016 (ACPE, 2015a) but allowed for a collaborative experience where multiple preceptors and students could come together from different locations to complete the experience remotely. The American Association of Colleges of Pharmacy (AACP) Core Entrustable Professional Activities (EPAs) for new pharmacy graduates (Haines et al., 2017), included in the ACPE Guidance document for Standards 2016 (ACPE, 2015b), guided the development of this alternative APPE to preserve the outcomes and delivery of the Pharm.D. curriculum. This APPE intentionally built upon the foundational knowledge, skills and abilities taught in the Pharm.D. curriculum regarding EBM, which meets ACPE Standards 2016, addresses CAPE outcomes, and three of the EPA core domains 
(Medina et al., 2013; ACPE, 2016a; Haines et al., 2017). The CAPE outcomes addressed in this EBM APPE include domains 1.1-Foundational knowledge, 3.1- Problemsolving, 3.2-Educator, 3.6-Communication, 4.1-Selfawareness, 4.2-Leadership and 4.4-Professionalism
(Table I) (Medina et al., 2013). The EPAs that are addressed in this EBM APPE include Domains 1-Patient care provider, 4-Information master, and 6-Self developer (Table I) (Haines et al., 2017).

Table I: Entrustable Professional Activities (EPAs) and Center for the Advancement of Pharmacy Education (CAPE) educational outcomes 2013 addressed by Advanced Pharmacy Practice Experience (APPE) activities

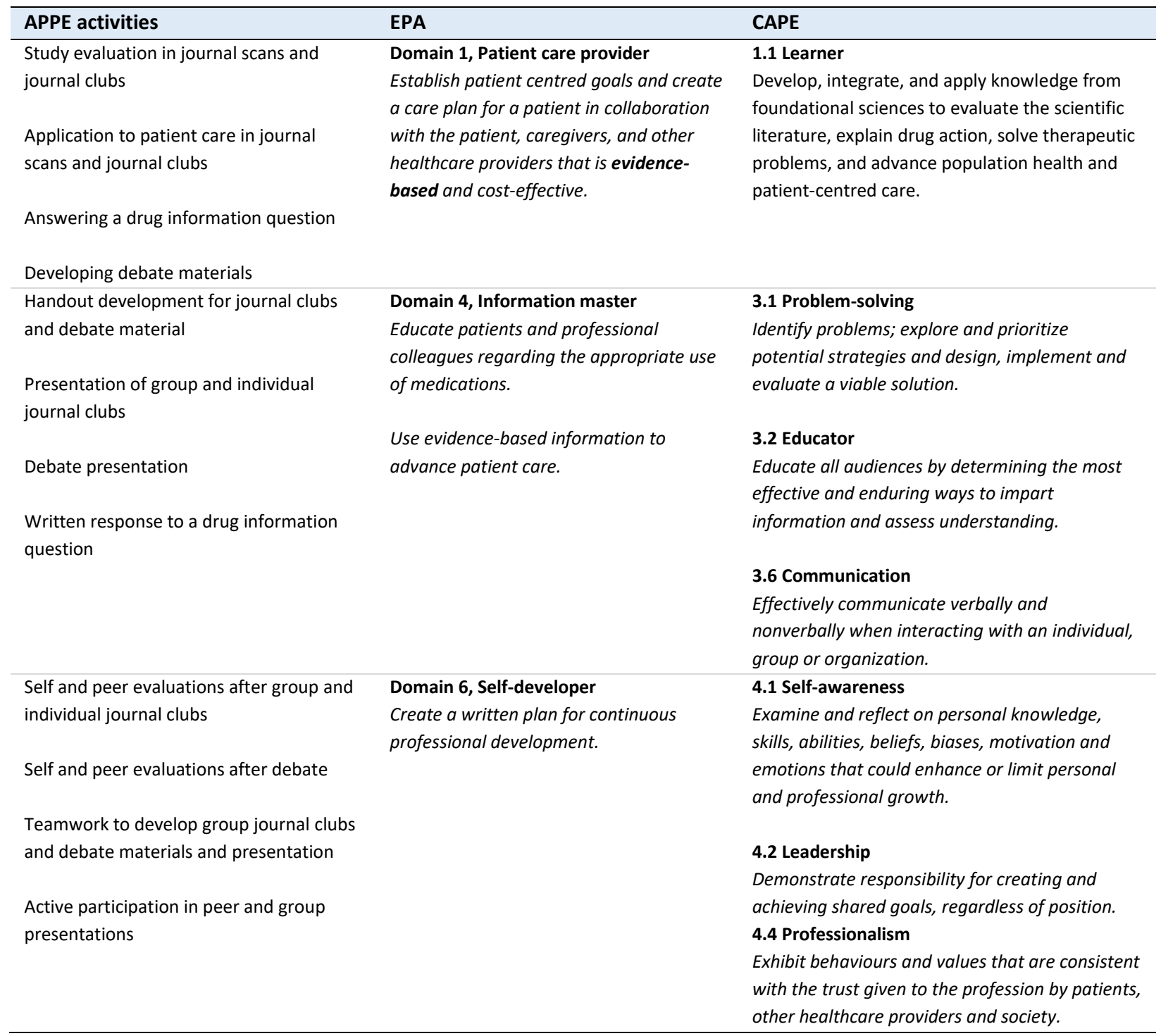

The purpose of this descriptive report is to discuss the development, implementation, structure, and evaluation of this EBM APPE, as well as recommendations and lessons learned for faculty or preceptors considering implementing a similar rotation. The structure and recommendations of this experience could be adapted to other APPEs to be offered on a routine basis.

\section{Description}

Seven faculty preceptors located in different areas in the Department of Pharmacy Practice developed a fiveweek EBM APPE, utilising videoconferencing technology. The group was comprised of three inpatient internal medicine faculty, three ambulatory care faculty, and the executive director of experiential programs. The group began preliminary discussions in early April 2020, allowing for six weeks to design the APPE prior to implementation. The goal was an experience that meets requirements similar to a drug 
information (DI) rotation while expanding upon the students' EBM foundation with a high-level clinical application focus. The global learning outcomes, developed at the conclusion of the rotation design process, are included in Table II. These learning outcomes served as the foundation for all activities and assessments. Also, each activity was linked to the rotation's assigned EPAs (Table I) and the required assessment areas: Communication and Collaboration,
Critical thinking and Problem solving, Management/ organisational skills, and Self-awareness and development. The group met every other week for approximately two hours to discuss the global learning outcomes, progress, logistics, and activities involved in the rotation. The time in between allowed for the development of the syllabus, learning activities, and assessments.

Table II: Global learning outcomes for an evidence-based medicine advanced pharmacy practice experience

1. Analyse appropriate resource(s) to answer drug information questions.

2. Formulate a response to a drug information question.

3. Communicate the answer to a drug information question to a health care provider, patient, and/or caregiver in writing and/or verbally at an appropriate level.

4. Utilise professional writing skills in completion of all assigned projects.

5. Analyse biomedical literature to determine if a study is valid and significant enough to change clinical practice.

6. Demonstrate effective verbal and non-verbal skills with other healthcare professionals and students appropriate to the setting.

\section{Rotation structure}

For the initial iteration of the APPE, two to three students were assigned to each faculty member (18 students total). Students and faculty resided in multiple locations across the state of Alabama. All seven faculty members were responsible for student activities and assessment of students in some capacity during the rotation. A course management platform was used to organise all rotation communication, content, activities, and assignments. Prior to the start of the rotation, students were encouraged to review the EBM material taught during the first three professional years of the Pharm.D. curriculum. Access to previous course work and recordings were available throughout the rotation on the APPE course management platform.

Students met formally two to three days per week with assigned preceptors. Responsibilities rotated each week to decrease the workload on each individual faculty member. Rotation activities, detailed below, used a combination of group and individual work and integrated opportunities for self and peer evaluation and reflection. All rotation sessions were designed to be discussion-based, and students were expected to engage and participate in the discussion of all assigned readings and topics. Discussion forums were used to answer rotation questions outside of formal meeting times. Individual preceptors could also meet with students one-on-one to provide global and studentspecific feedback. Students were thoroughly oriented to a detailed schedule of all activities, assessments, rubrics, and expectations on the first day of the rotation (Tables III and IV).

\section{Learning activities and evaluation}

All activities and assessments (Table III) provided the students with opportunities to evaluate scientific literature, perform evidence-based clinical reasoning, and develop an evidence-based approach to patient care. Students were evaluated on learning outcome achievement utilising rubrics. Faculty leveraged and modified existing rubrics utilised in the Pharm.D. curriculum for consistency of assessments between faculty. The faculty provided students with explicit instructions and expectations for each assessment, including formal assignment and presentation examples. Students received detailed written feedback and optional verbal feedback following each learning activity and corresponding assessment. Faculty completed all assessments by consensus.

Throughout the rotation, students were evaluated on their participation in all rotation activities, discussions, and self and peer evaluations. Participation feedback, evaluated by faculty with a rubric, was delivered weekly and included an assessment on the student's ability to complete responsibilities, participate during scheduled rotation sessions, participate in group activities, and complete all self and peer assessments. Each student received a weekly participation score corresponding with the lowest achieved rating (i.e. Not Done [0\%], Deficient [50\%], Accomplished [100\%]) in any criteria. Students submitted self and peer evaluations following each week's activities. Students were also required to complete the standardised journal club evaluation rubric following group and individual journal club presentations to reflect on their performance and compare to preceptor assessment. 
Table III: Student assignment and assessment structure

\begin{tabular}{|c|c|c|}
\hline Assignment description & Time of assessment & Type of assessment \\
\hline $\begin{array}{l}\text { Individual journal scan (9\%) } \\
\text { Each student individually prepared an } \\
\text { abbreviated handout on an assigned article }\end{array}$ & Weeks $1,2,3$ & $\begin{array}{l}\text { Formative utilising descriptive criteria for full } \\
\text { credit, } 1 / 2 \text { credit, or zero credit }\end{array}$ \\
\hline $\begin{array}{l}\text { Group journal club (15\%) } \\
\text { Students worked in groups of } 3 \text { to prepare a } \\
\text { handout and presentation on an assigned } \\
\text { article }\end{array}$ & Weeks 1, 2, 3 & Formative utilising a journal club rubric \\
\hline $\begin{array}{l}\text { Individual journal club with comparative } \\
\text { literature (25\%) } \\
\text { Each student prepared a handout and } \\
\text { presentation on a preceptor-approved article }\end{array}$ & Week 4 & Formative utilising a journal club rubric \\
\hline $\begin{array}{l}\text { Group debate (20\%) } \\
\text { Students worked in groups of three to prepare } \\
\text { a debate handout and presentation on an } \\
\text { assigned topic }\end{array}$ & Week 5 & Formative utilising a debate rubric \\
\hline $\begin{array}{l}\text { Drug information question response (15\%) } \\
\text { Students were given a drug information } \\
\text { question during the first week of the rotation } \\
\text { and were required to submit their response }\end{array}$ & Week 5 & $\begin{array}{l}\text { Formative utilising a drug information } \\
\text { question rubric }\end{array}$ \\
\hline $\begin{array}{l}\text { Pre-rotation assessment (3\%) } \\
\text { Students completed an individual pre-rotation } \\
\text { assessment }\end{array}$ & First day of the rotation & $\begin{array}{l}\text { Multiple choice and fill in the blank polling } \\
\text { software }\end{array}$ \\
\hline $\begin{array}{l}\text { Post-rotation assessment (3\%) } \\
\text { Students completed an individual post-rotation } \\
\text { assessment }\end{array}$ & Last day of the rotation & $\begin{array}{l}\text { Multiple choice and fill in the blank polling } \\
\text { software }\end{array}$ \\
\hline $\begin{array}{l}\text { Participation (10\%) } \\
\text { Students were evaluated on completing } \\
\text { responsibilities, participation, and their ability } \\
\text { to self-and peer-evaluate }\end{array}$ & Weekly & Formative with a participation rubric \\
\hline
\end{tabular}

Table IV: Rotation schedule and student assignments

\begin{tabular}{|c|c|c|c|}
\hline Week & Day & Application-based activities & Students responsible \\
\hline \multirow[t]{3}{*}{1} & Day 1 & Orientation \& preassessment & All \\
\hline & Day 2 & $\begin{array}{l}\text { Group journal clubs \& Individual } \\
\text { journal scans (Chronic Obstructive } \\
\text { Pulmonary Disease) }\end{array}$ & $\begin{array}{l}\text { Journal club: Groups 1, 2, } 3 \\
\text { Journal scan: Groups 4, 5, } 6\end{array}$ \\
\hline & Day 3 & $\begin{array}{l}\text { Group journal clubs \& Individual } \\
\text { journal scans (Antiplatelet Therapy in } \\
\text { Acute Coronary Syndrome) }\end{array}$ & $\begin{array}{l}\text { Journal club: Groups 4, 5, } 6 \\
\text { Journal scan: Groups 1, 2, } 3\end{array}$ \\
\hline \multirow[t]{2}{*}{2} & Day 1 & $\begin{array}{l}\text { Group journal clubs \& Individual } \\
\text { journal scans (Non-statin Therapies in } \\
\text { Dyslipidemia) }\end{array}$ & $\begin{array}{l}\text { Journal club: Groups 1, 2, } 3 \\
\text { Journal scan: Groups 4, 5, } 6\end{array}$ \\
\hline & Day 2 & $\begin{array}{l}\text { Group journal clubs \& Individual } \\
\text { journal scans (Proton-pump Inhibitors) }\end{array}$ & $\begin{array}{l}\text { Journal club: Groups 4, 5, } 6 \\
\text { Journal scan: Groups 1, 2, } 3\end{array}$ \\
\hline \multirow[t]{2}{*}{3} & Day 1 & $\begin{array}{l}\text { Group journal clubs \& Individual } \\
\text { journal scans (Direct Oral } \\
\text { Anticoagulants in Atrial Fibrillation) }\end{array}$ & $\begin{array}{l}\text { Journal club: Groups 1, 2, } 3 \\
\text { Journal scan: Groups 4, 5, } 6\end{array}$ \\
\hline & Day 2 & $\begin{array}{l}\text { Group journal clubs \& Individual } \\
\text { journal scans (Pre-diabetes) }\end{array}$ & $\begin{array}{l}\text { Journal club: Groups 4, 5, } 6 \\
\text { Journal scan: Groups 1, 2, } 3\end{array}$ \\
\hline \multirow[t]{6}{*}{4} & Day 1 & Individual journal clubs & Members of group 1 \\
\hline & Day 1 & Individual journal clubs & Members of group 2 \\
\hline & Day 2 & Individual journal clubs & Members of group 3 \\
\hline & Day 2 & Individual journal clubs & Members of group 4 \\
\hline & Day 3 & Individual journal clubs & Members of group 5 \\
\hline & Day 3 & Individual journal clubs & Members of group 6 \\
\hline \multirow[t]{5}{*}{5} & Day 1 & DI question due & All \\
\hline & Day 2 & Debates & Debate groups 1 and 2 \\
\hline & Day 2 & Debates & Debate groups 3 and 4 \\
\hline & Day 2 & Debates & Debate groups 5 and 6 \\
\hline & Day 3 & Post assessment \& final evaluations & All \\
\hline
\end{tabular}


During the first three weeks of the rotation, students were randomly assigned to six groups of three to participate in focused journal club discussions on an assigned topic area. Topics were selected by faculty preceptors and purposefully incorporated both inpatient and outpatient perspectives (Table IV). After each presented article, students were expected to make specific recommendations and answer questions regarding application to patient care. A total of six focused discussions occurred during these three weeks. For each session, required background reading and three primary literature articles were provided. Two groups were assigned to each article. One group was required to prepare and present a journal club, and the individual members of the other group were required to submit a "journal scan", which entailed responses to guided discussion questions on the same article. Individual group members presenting the journal club did not receive section presentation assignments until the start of their presentation. This process ensured all group members came prepared to present all sections of the article and encouraged individual accountability. All students were expected to read all articles and actively participate in the discussion following each journal club as a component of their participation score. Two preceptors facilitated discussion during each session with an effort to correlate the application of each article to evidence-based treatment recommendations for each topic. Journal club presentations were evaluated with a standardised journal club rubric for consistency. Journal scan handouts were evaluated as complete (100\%), partially complete $(50 \%)$, or incomplete/not done $(0 \%)$ based on effort and completeness.

During week four, students participated in individual journal club presentations, where they had to select an article published within the previous year and obtain preceptor approval. Each presentation was required to have comparative literature. Students were evaluated utilising the standardised journal club rubric. All students were provided with the articles in advance and were expected to analyse the clinical trial and come prepared to ask questions and engage in discussion. Each session was facilitated by two preceptors.

During week five, students worked in assigned groups of three to participate in a debate, with each session being facilitated by three preceptors. The debate topic and the primary accompanying article was assigned the first week of the rotation, and a clinical case served as the focus of the debate. Students were expected to develop an argument to support their assigned position, which included evidence provided, in addition to two studies supporting their stance. Students were also expected to submit potential questions to ask the opposing team during the rebuttal portion of the debate. The debate followed the Lincoln-Douglas format. All group members were expected to participate. A debate rubric was used for standardisation in grading.

Also, during week five, students were expected to formally answer and submit an assigned drug information question in writing. Students were provided with the question during the first week of the rotation and were able, but not required, to submit draft versions for preceptor feedback. Students were formally evaluated using a drug information question rubric by their preceptor of record.

Lastly, students were required to complete both a preand post-assessment on the first and last day of the rotation. This assessment included multiple-choice and fill-in-the-blank questions. Polling software was used to administer both assessments during a live session. The goal of these assessments was to hold students accountable for EBM course work taught in the Pharm.D. curriculum and to assess the progression in their ability to interpret and apply evidence-based principles to patient care over the course of this rotation. Questions were different on the postassessment but similar in content and skill focus. Every student received a final APPE evaluation from their preceptor of record based on scores received throughout the rotation (Table III).

\section{Faculty or preceptor workload}

Over the course of the five-week rotation, each faculty preceptor served as a primary preceptor and evaluator for one group journal club (weeks 1-3) and one individual journal club session (week 4). These sessions lasted approximately three hours each, with one to two hours needed for grading afterwards. Furthermore, preparation for each session varied based on preceptor topic experience but generally included reviewing tertiary resources, therapeutic guidelines, the journal club articles and student handouts, and developing supplementary materials (i.e. slides), which required several hours. Additionally, each faculty served as a secondary preceptor and evaluator for one group journal club and one individual journal club session. Approximately half the time was needed to prepare for and grade these sessions as the secondary preceptor. Finally, one faculty preceptor served as the primary evaluator and organiser for all three debate sessions, and all other faculty served as secondary evaluators. Each debate session lasted approximately one hour, with an additional hour spent grading following the debate. Other times needed included grading or providing feedback for the drug information question, assessing journal scan handouts, peer evaluations, individual participation, and fielding questions from students for various assignments. 


\section{Discussion}

The goal of a Pharm.D. curriculum is to develop students from the first year through APPEs who are practice-ready to assume the responsibilities of a pharmacist upon graduation (ACPE, 2016a; ACPE, 2016b, ASHP, 2020; Boyce et al., 2020). Evaluation and application of EBM principles is a critical area to introduce. It provides students with opportunities to apply this concept throughout a Pharm.D. curriculum, preparing them to use these principles in direct patient care.

The intentional design of this EBM APPE allowed for seamless execution by this collaborative group of faculty preceptors. Student groups of three worked well for this first iteration, striking a balance between individual accountability with class size and faculty or preceptor workload. Groups in increments of three also allowed for an even number of groups participating, which could also be accomplished with 12 students, 24 students, etc. Although seven faculty preceptors were responsible for 18 students, this concept could also be realised with more or fewer faculty or preceptors, depending on the structure of the rotation and the level of involvement with grading desired. It might be beneficial to start this type of rotation with more faculty or preceptors and execute with fewer members once activities and topics have been designed. Overall, this group of faculty preceptors felt there was a good balance of both student responsibilities and time commitment, as well as faculty involvement and student contact with this iteration.

Strengths of this APPE included faculty collaboration, individual and group student activities, flexibility with remote learning, variety of activities and topics explored, and faculty workload expectations. Based on the preceptors' topic experience and practice settings, preceptor selection of all topics and journal articles may be preferred from the perspective of workload and preparation. Additionally, the variety in topics and literature reviewed allowed for different types of studies to be explored. For example, one session was focused on non-inferiority trials while others included cohort studies that assessed harm, or those with patient-year outcomes, allowing students to be challenged consistently and exposed to different types of literature.

The primary limitation of this APPE was the difficulty to assess the knowledge of each student regularly, despite regular and scheduled interactions. With 18 students, it is difficult to question individual students as one would with one to three students on a traditional APPE. However, the assessment of students far exceeded a traditional classroom experience. Additionally, it was challenging for the faculty preceptors to learn as much about each individual student as they would on a traditional APPE, so smaller numbers, with similar preceptor to student ratios (1:2-3), may be desirable.

\section{Evaluation}

Student perceptions regarding EBM skills were collected via a survey several weeks after the EBM APPE. The survey sought to collect information on confidence with EBM skills after the APPE and student perceptions regarding the course. Six of eighteen (33\%) students responded to the survey. Students were most confident with critical evaluation of primary literature and their ability to self-assess their presentations. Students reported that the individual journal club presentation was the most valuable experience and that the journal scans were the least valuable. The time required to complete $A P P E$ activities ranged from 30 to 60 hours. Finally, students responded positively to the number of students/faculty, but some stated they would not exceed 18 students.

Student performance on the pre-and post-assessment was collected to assess baseline knowledge of EBM concepts retained from the pre-APPE curriculum and changes in knowledge at the conclusion of the APPE. Mean scores for the pre-and post-assessments were $26 / 30(87 \%)$ and $27.3 / 30(91 \%)$, respectively. This result represented a mean change of 1.33 points (95\% Cl: $1.33-3.79$ [P=0.28]). The majority of students either improved their score $(6 / 18)$ or were unchanged (10/18), while two students' scores decreased.

\section{Future plans}

This EBM APPE provides students repeated opportunities to evaluate the medical literature on a variety of topics through individual journal scans, group journal clubs, an individual journal club, answering a drug information question and participation in a therapeutic debate. They are required to consider clinical, economic, and humanistic outcomes as they make recommendations based on their evaluation of the primary literature. Students are challenged to defend their conclusions and applications through question-and-answer sessions with their peers and faculty or preceptors in attendance for journal club presentations and the debate. These activities allow students to develop information mastery and consider the patient care and population applications over the course of the five-week APPE (Haines et al., 2017). In addition, they serve as health educators to their 17 peers and the seven faculty within the rotation through handout development, presentations, debates and a 
written drug information response. Finally, they are held accountable for professional development through active participation in all group handouts, presentations, debate preparation and delivery. They are also required to complete self- and peerassessments weekly throughout the rotation. These fostered becoming a self-developer through professional and personal assessment and development (Haines et al., 2017). Students that complete an APPE structured like the EBM one described in this paper should be practice ready to apply EBM principles to patient care. Overall, the development, implementation, and structure of this EBM APPE may assist other faculty or preceptors in creating similar innovative required APPEs based on their school needs.

\section{References}

American Council for Pharmacy Education. (2015). Accreditation standards and key elements for the professional program in pharmacy leading to the Doctor of Pharmacy degree. https://www.acpeaccredit.org/pdf/Standards2016FINAL.pdf

American Council for Pharmacy Education. (2015) Guidance for the accreditation standards and key elements for the professional program in pharmacy leading to the Doctor of Pharmacy degree. https://www.acpe-

accredit.org/pdf/GuidanceforStandards2016FINAL.pdf

American Society of Health-System Pharmacists. (2020). ASHP long-range vision for the pharmacy workforce in hospitals and health systems. American Journal of HealthSystem Pharmacy, 77(5), 386-400.

https://doi.org/10.1093/ajhp/zxz312

Boyce, E.G., Harris, C.S., Bingham, A.L., Chan, E., Chapman, S.A., Chilbert, M.R., Dy-Borman, E., Haines, S.T., Heavner, M.S., Marcus, K.B., Smith, S.E., Strnad, K., \& Yunker, N.S. (2020). Striving for excellence in experiential education. Journal of the American College of Clinical Pharmacy, 3(3),

678-691. https://doi.org/10.1002/jac5.1240

Haines, S. T., Pittenger, A. L., Stolte, S. K., Plaza, C. M., Gleason, B. L., Kantorovich, A., McCollum, M., Trujillo, J. M., Copeland, D. A., Lacroix, M. M., Masuda, Q. N., Mbi, P., Medina, M. S., \& Miller, S. M. (2017). Core entrustable professional activities for new pharmacy graduates. American Journal of Pharmaceutical Education, 81(1), S2. https://doi.org/10.5688/ajpe811S2

Medina, M. S., Plaza, C. M., Stowe, C. D., Robinson, E. T., DeLander, G., Beck, D. E., Melchert, R. B., Supernaw, R. B., Roche, V. F., Gleason, B. L., Strong, M. N., Bain, A., Meyer, G. E., Dong, B. J., Rochon, J., \& Johnston, P. (2013). Center for the advancement of pharmacy education 2013 educational outcomes. American Journal of Pharmaceutical Education, 77(8), 162. https://doi.org/10.5688/ajpe778162 